\title{
Rapid transport of seminal immunoglobulin to distal parts of the female reproductive tract in rabbits
}

\author{
D. Jappel
}

Laboratory of Evolutionary Biology, Czechoslovak Academy of Sciences, Na Folimance 11, 12000

Prague 2, Czechoslovakia

\begin{abstract}
Summary. Bucks immunized with the bacteriophage-cloning vector fd-tet display strong humoral seminal immunity of $1.5 \times 10^{6} \mathrm{fd}$-tet neutralizing units $(\mathrm{nu}) \mathrm{ml}^{-1}$. We used this model to study the distribution of seminal immunoglobulin in the female reproductive tract after copulation and artificial insemination. In contrast to artificial insemination, significant $(P<0.01)$ amounts $\left(147 \mathrm{nu} \mathrm{ml} \mathrm{ml}^{-1}\right.$, i.e. about $1.25 \times 10^{-4}$ input ejaculate) of neutralizing activity reached the uterus within $20 \mathrm{~min}$ of a single copulation, which is evidence for rapid transport of seminal plasma to distal parts of the tract. Oviducts were also quickly impregnated with antibodies to fd-tet, which persist in the distal compartments for at least $24 \mathrm{~h}$.
\end{abstract}

Keywords: semen; immunoglobulin; rabbit

\section{Introduction}

Rapid sperm transport occurs in mammalian species, but its biological significance is poorly understood. As it is usually not directly involved in fertilization, it might be viewed as an epiphenomenon of pericoital events occurring in the female tract. However, Overstreet (1983) suggested that rapidly transported spermatozoa could act as local messengers to the female reproductive tract in preparing it for sperm migration, fertilization and implantation. Pandya \& Cohen (1985) showed that women, like rabbits, respond to cervical deposition of spermatozoa by leukocytosis within $15 \mathrm{~min}$.

It is uncertain whether seminal plasma participates in rapid transport in humans and rabbits. Resolution of this question is essential to an appraisal of possible factors that could 'prime' the female tract to perform its reproductive functions. Early experiments using dyes, particles and radio-opaque media as markers of seminal fluid gave inconsistent results. Krehbiel \& Carstens (1939) observed mass movement of contrast medium through the cervix into the uterus of supinerestrained does, but Noyes et al. (1958) obtained different results. In an attempt to reconcile these findings, Akester \& Inkster (1961) described two types of entry of radio-opaque medium into the uterus: the type of Krehbiel \& Carstens, which takes place within 2 min of vulval stimulation, could be ascribed to abnormal conditions of animal restrainment whereas minute projections of opaque material through the cervices lasting for several hours could be observed after mating or vulval stimulation of unrestrained does. Asch et al. (1977) noticed the failure of seminal plasma to enter the uterus and oviducts of rabbit does artificially inseminated with radiolabelled semen containing unlabelled spermatozoa.

In this study, we investigated whether, after copulation, neutralizing immunoglobulin G (IgG) from seminal fluid of bucks hyperimmune to bacteriophage fd-tet is rapidly transported to the uterus and oviducts. This investigation might be relevant to understanding the role of seminal antibodies in transmission of diseases such as acquired immune deficiency syndrome (AIDS). 


\section{Materials and Methods}

\section{Neutralization titration}

Fd-tet is a bacteriophage-cloning vector which confers tetracycline resistance to infected hosts (Zacher III et al., 1980). The methods of its propagation and purification have been described elsewhere (Smith, 1988). The neutralizing titre of the sample was scored as the dilution that caused $50 \%$ inhibition of a standard amount of about 50 tetracycline-resistance-transducing units (tu) of fd-tet; $50 \mu \mathrm{l}$ of serial twofold sample dilutions were mixed with $50 \mu \mathrm{l}$ of phosphate-buffered saline with $1 \%$ bovine serum albumin (PBS/BSA) containing 250 tu fd-tet. After incubation for $2 \mathrm{~h}$ at room temperature, a drop of indicator Escherichia coli K91 was added and $25 \mu \mathrm{l}$ aliquots were poured onto tetracycline agar in 24-well plastic Costar plates. Each sample was assayed in quadruplicate.

\section{Animals and treatments}

Three adult Big Chinchilla (a commercial breed of rabbit introduced to Czechoslovakia in 1922 from Germany and distributed by VELAZ Prague) bucks were immunized with CsCl-gradient purified fd-tet as follows: first, $5 \mu \mathrm{g}$ in $250 \mu \mathrm{l}$ PBS intravenously (i.v.), then two doses of $10 \mathrm{mg}$ in $5 \mathrm{ml}$ PBS intraperitoneally (i.p.) at intervals of 14 days. After this treatment, the seminal fluid titre reached a basal plateau of $5 \times 10^{5} \mathrm{nu} \mathrm{ml} 1$, which could be boosted to $1.5 \times 10^{6} \mathrm{nu} \mathrm{ml} \mathrm{m}^{-1}$ with $10 \mathrm{mg}$ fd-tet i.p. This maximum titre persisted from day 10 to day 23 after the booster injection. At this time the bucks were mated once to virgin adult does or used for ejaculate collection with artificial vaginas (Adams, 1972); $0.8 \mathrm{ml}$ of pooled fresh ejaculates were used for artificial insemination (Adams, 1972) of receptive females. No leakage was observed. Seminal fluid was obtained for immunological analysis by clarifying ejaculates at $14000 \mathrm{~g}$ for $3 \mathrm{~min}$. Immunoglobulin-class determination was achieved by fractionation on Ultrogel AcA-34 (LKB) (Peri et al., 1982). Femates were killed by an overdose of thiopental (Spofa) i.v. at intervals of $20 \mathrm{~min}, 4.5 \mathrm{~h}$ and $24 \mathrm{~h}$ after insemination, using three specimens for each interval and type of insemination.

Immediately after opening the abdomen, clamps were placed at both ends of the cervices, the uterotubal junctions and the ends of the oviducts. All precautions (Overstreet \& Cooper, 1978) to prevent contamination and other artefacts of handling were carefully observed. The uterine and cervical lumina were flushed with $1 \mathrm{ml}$ PBS/BSA and the oviducts with $0.5 \mathrm{ml}$ of the same solution. Samples were centrifuged for $3 \mathrm{~min}$ at $14000 \mathrm{~g}$, the supernatant was titrated for neutralization and the sediment inspected for presence of spermatozoa.

\section{Results}

The ejaculates contained $(1-5) \times 10^{8}$ spermatozoa $\mathrm{ml}^{-1}$ of which $30-40 \%$ were nonmotile. The seminal fd-tet-neutralizing response is associated with $\mathrm{IgG}$ and not with the cellular fraction of the semen (Table 1). In contrast to artificial insemination, significant $(P<0.01)$ amounts of this immunity reached distal parts of the female reproductive tract within 20 min of copulation and remained there for at least $24 \mathrm{~h}$ (Table 2). In control does inseminated with nonimmune semen, the fd-tet neutralizing activity was below the detection limit of $20 \mathrm{nu} \mathrm{ml} \mathrm{m}^{-1}$ throughout the tract.

Table 1. Fd-tet neutralizing properties of ejaculate of hyperimmune rabbit bucks

\begin{tabular}{lc}
\hline $\begin{array}{l}\text { Maximum neutralizing titre } \\
\text { of the fluid fraction } \\
\text { (neutralizing units }(\mathrm{nu})\end{array}$ & $1.52 \times 10^{6} \pm 3.7 \times 10^{5}$ \\
$\mathrm{ml}^{-1}$ ) consisting of: & $>99.93$ \\
IgG fraction (\%) & $<0.07$ \\
IgA fraction (\%) & \multicolumn{1}{c}{$\begin{array}{c} \\
\text { Titre associated with the }\end{array}$} \\
$\begin{array}{l}\text { cellulart fraction (nu } \\
\mathrm{ml}^{-1} \text { ) }\end{array}$ & i.e. $\leqslant 0.53 \%$ of total \\
\hline
\end{tabular}

Ig: immunoglobulin.

† Sediment obtained after clarification of ejaculate at $14000 \mathrm{~g}$ for $3 \mathrm{~min}$ 
Table 2. Regional distribution of seminal fd-tet neutralizing antibodies in the reproductive tract of female rabbits at various intervals after copulation or artificial insemination (nu ml-1)

\begin{tabular}{|c|c|c|c|c|}
\hline \multirow[t]{2}{*}{ Region } & \multirow[t]{2}{*}{ Insemination } & \multicolumn{3}{|c|}{ Time after insemination } \\
\hline & & $20 \mathrm{~min}$ & $4.5 \mathrm{~h}$ & $24 \mathrm{~h}$ \\
\hline Cervix & Natural & $5120 \pm 1280$ & $3840 \pm 1280$ & $1492 \pm 368$ \\
\hline & Artificial* & $747 \pm 184$ & $747 \pm 184$ & $320 \pm 68$ \\
\hline Uterus & $\begin{array}{l}\text { Natural } \\
\text { Artificial* }\end{array}$ & $147 \underset{<20}{ \pm} 23$ & $187 \underset{<20}{ \pm} 115$ & $\begin{array}{c}67 \pm 24 \\
<20\end{array}$ \\
\hline Oviducts & $\begin{array}{l}\text { Natural } \\
\text { Artificial* }\end{array}$ & $\underset{<20}{54 \pm} 24$ & $\underset{<20}{60 \pm} 20$ & $\begin{array}{l}<20 \\
<20\end{array}$ \\
\hline
\end{tabular}

$* 0.8 \mathrm{ml}$ of fresh immune ejaculate of titre $1.5 \times 10^{6} \mathrm{nu} \mathrm{ml}^{-1}$ was used for artificial insemination of receptive does.

Ten days after copulation ad libitum (3-5 times), $160 \mathrm{nu} \mathrm{ml}^{-1}$ was still present in the fluid aspirated from the cranial end of the vagina. The distribution of spermatozoa in the flushed compartments was assessed at the level of orders of magnitude and no significant difference between mating and artificial insemination was observed. The occurrence of rapid sperm transport after both types of insemination was confirmed by the recovery of up to 300 spermatozoa from the uterus and oviducts after $20 \mathrm{~min}$. At $4.5 \mathrm{~h}$ the uteri contained about $10^{6}$ spermatozoa. However, the methods of sample collection were not designed for accurate determination of numbers of spermatozoa but for maximum antibody elution.

\section{Discussion}

We have shown that, in contrast to artificial insemination, about $1.0 \times 10^{-4}$ ejaculated seminal fluid is rapidly transported to the uterus after copulation of rabbits.

Artefacts of handling of the reproductive tract are therefore not a likely source of the positive result. It will also not be due to transport of IgG adherent to spermatozoa, as the increase in their number in the uterus is not concomitant with a rise in neutralizing activity.

The negative outcome of the experiment of Asch et al. (1977) was based on a detection limit of $1.5 \times 10^{-4} \mathrm{ml}$ of seminal fluid in the distal reproductive tract. Our approach offers a higher sensitivity, as $2.5 \times 10^{-5} \mathrm{ml}$ of seminal fluid could be traced. The contrasting positive result can be best explained by the different efficiency of transport of seminal plasma after copulation or AI. Similar results with both techniques were obtained by increasing the neutralizing titre of the artificial inseminate at least 50 times by admixture of immune IgG isolated from serum. This shows that seminal fluid may reach distal parts of the reproductive tract even after artificial insemination, although in much smaller amounts. These observations are inconsistent with the similarity between the uterine and oviductal sperm counts after copulation and artificial insemination. We assume that this discrepancy is due to physiological, rather than technical, factors since Overstreet \& Cooper (1978) also failed to observe a substantial difference between these parameters.

In rabbits, the cervix functions as a valve with only a potential space between its apposing mucosal folds, the numerous overlapping cilia of which are vigorously beating towards the vagina (Blandau, 1977). The initial transport of ejaculate through the cervix is mediated by contractions of the reproductive tract (Fuchs, 1972). In this complex rheological system, what holds for the particulate cellular components of semen need not hold for seminal plasma. There is evidence that the rapid delivery of spermatozoa into the upper reproductive tract is a quantized process. Overstreet \& Tom (1982), inseminated rabbit does with whole semen and with killed spermatozoa suspended in seminal plasma at roughly similar sperm inputs; $15 \mathrm{~min}$ later, the cervices contained 
$2.1 \times 10^{6}$ spermatozoa in the former case, but only $7 \cdot 3 \times 10^{4}$ in the latter. The efficiency of sperm recovery from the oviducts was nevertheless the same in both cases. Another example of quantization of rapid sperm transport is its asymmetry (Overstreet \& Cooper, 1978). These phenomena are probably due to the spatial and hydrodynamic characteristics of the interaction of sperm particles with the bottlenecks of the distal tract (Katz et al., 1989). In contrast to the complex behaviour of spermatozoa, small amounts of seminal fluid may simply be permeated through the cervical sluice during the initial phase of transport. This leakage may be proportional to the receptive pericoital activity of the female reproductive tract. We understand it to be more pronounced during copulation, as the mere presence of a buck can elicit uterine contractions (Fuchs, 1972)-a factor which is obviously missing at AI.

The salient fact revealed by this study is that the transit of seminal plasma into distal parts of the female reproductive tract is confined to the rapid phase of transport only.

Our finding of transport of seminal fluid markers in rabbits is in agreement with similar results in other species: cows (Rowson, 1955), gilts (Einarsson et al., 1980) and man (De Boer, 1972). However, in contrast to the methods used in the previous reports on this matter, our approach does not interfere with the natural course of insemination. It can also be successfully applied to other animals. We found much more pronounced impregnation of the uterus with inseminated antibodies in mice than in rabbits (D. Jappel, unpublished).

As Barratt et al. (1990) describe the presence of $10^{6}$ leucocytes (T cells, monocyte-macrophages and others) $\mathrm{ml}^{-1}$ semen, at least three factors may be considered as chemical signals along the entire female reproductive tract: spermatozoa, other seminal cellular components and constituents of seminal plasma.

The possibility that small quantities of immunocompetent molecules and cells reach distal parts of the female tract may relate to the mechanisms of sexual transmission of viral infections. Complex patterns of humoral and local secretory immunity to HIV have been observed in semen of seropositive individuals (Belec et al., 1989) and low concentrations of specific antibodies have been shown to enhance HIV infectivity (Takeda et al., 1988).

Our study shows that the relative concentrations of inseminated components vary dramatically along different compartments of the female reproductive tract, which may strongly influence their role in establishment of infection.

\section{References}

Adams, C.E. (1972) Induction of ovulation and A.I. techniques in the rabbit. Veterinary Record 91, 194-197.

Akester, A.R. \& Inkster, I.J. (1961) Cine-radiographic studies of the genital tract of the rabbit. Journal of Reproduction and Fertility 2, 507-508.

Asch, R.H., Balmaceda, J. \& Pauerstein, C.J. (1977) Failure of seminal plasma to enter the uterus and oviducts of the rabbit following artificial insemination. Fertility and Sterility 28, 671-673.

Barratt, C.L.R., Bolton, A.E. \& Cooke, I.D. (1990) Functional significance of white blood cells in male and female reproductive tract. Human Reproduction 5, 639-648.

Belec, L., Georges, A.J., Steenman, G. \& Martin, P.M.V. (1989) Antibodies to human immunodeficiency virus in the semen of heterosexual men. Journal of Infectious Diseases 159, 324-327.

Blandau, R.J. (1977) Comparative morphology and physiology of the cervix in several different animals and their relationship to sperm transport. In The Uterine Cervix in Reproduction, pp. 36-43. Eds V. Insler \& G. Bettendorf. Thieme, Stuttgart.
De Boer, C.H. (1972) Transport of particulate matter through the human female genital tract. Journal of Reproduction and Fertility. 28, 295-297.

Einarsson, S., Jones, B., Larsson, K. \& Viring, S. (1980) Distribution of small- and medium-sized molecules within the genital tract of artificially inseminated gilts. Journal of Reproduction and Fertility 59, $453-457$.

Fuchs, A.-R. (1972) Uterine activity during and after mating in the rabbit. Fertility and Sterility 23, 915923.

Katz, D.F., Drobnis, E.Z. \& Overstreet, J.W. (1989) Factors regulating mammalian sperm migration through the female reproductive tract and oocyte vestments. Gamete Research 22, 443-469.

Krehbiel, R.H. \& Carstens, S.G.P. (1939) Roentgen studies of the mechanism involved in sperm transport in the female rabbit. American Journal of Physiology 125, 571-586.

Noyes, R.W., Adams, C.E. \& Walton, A. (1958) Transport of spermatozoa into the uterus of the rabbit. Fertility and Sterility 9, 288-299. 
Overstreet, J.W. (1983) Transport of gametes in the reproductive tract of the female mammal. In Mechanism and Control of Animal Fertilization, pp. 499-543. Ed. J. F. Hartman. Academic Press, New York.

Overstreet, J.W. \& Cooper, G.W. (1978) Sperm transport in the reproductive tract of the female rabbit: $I$. The rapid transit phase of transport. Biology of Reproduction 19, $101-114$.

Overstreet, J.W. \& Tom, R.A. (1982) Experimental studies of rapid sperm transport in rabbits. Journal of Reproduction and Fertility 66, 601-606.

Pandya I.J. \& Cohen, J. (1985) The leukocytic reaction of the human uterine cervix to spermatozoa. Fertility and Sterility 43, 417-421.

Peri, B.A., Theodore, Ch.M., Losonsky, G.A., Fishaut, J.M., Rothberg, R.M. \& Ogra, P.L. (1982) Antibody content of rabbit milk and serum following inhalation or ingestion of respiratory syncytial virus and bovine serum albumin. Clinical and Experimental Immunology 48, 91-101.

Rowson, L.E.A. (1955) The movement of radio-opaque material in the bovine uterine tract. British Veterinary Journal 111, 334-342.

Smith, G.P. (1988) Filamentous phage assembly: morphogenetically defective mutants that do not kill the host. Virology 167, 156-165.

Takeda, A., Tuazon, C.U. \& Ennis, F.A. (1988) Antibody-enhanced infection by HIV-1 via Fc receptormediated entry. Science 242, 580-583.

Zacher III, A.N., Stock, C.A., Golden II, J.W. \& Smith, G.P. (1980) A new filamentous phage cloning vector: fd-tet. Gene 9, 127-140.

Received 22 July 1991 